\title{
A EXPERIÊNCIA CURRICULAR NO MESTRADO PROFISSIONAL : O DESAFIO DA CONSTRUÇÃO DE PONTES
}

Experience in professional course masters: the challenge of building bridges

\section{SOBRAL, Joao, DOUTOR}

Universidade da Região de Joinville - Univille I sobral41@gmail.com

\section{CAVALCANTI ,Anna I MESTRE}

Universidade da Região de Joinville - Univille I anna.cavalcanti08@gmail.com

\section{PEREIRA, Irma}

Universidade da Região de Joinville - Univille I irma.haensch@gmail.com

\section{MATTEI , Gianna}

Universidade da Região de Joinville - Univille I giannamattei91@gmail.com

\section{Resumo}

Este artigo tem como objetivo expor e fazer uma reflexão sobre os mestrados profissionais vistos do lugar do design. Reforça a necessidade da construção de pontes entre empresas e universidades rumo à inovação e as mudanças de paradigmas impostas à academia e ao setor produtivo, além dos riscos que estes processos podem apresentar ao sistema de ensino e pesquisa universitária.

Palavras Chave: Mestrado profissional; Design; Educação; Inovação

\section{Abstract}

This article aims to expose and make a reflection on professional visas masters of the place of design. Reinforces the need to build bridges between companies and universities towards innovation and paradigm shifts imposed on the academia and the productive sector and risks that these processes may present to the education system and university research.

Keywords: Professional master; Design; education; innovation 


\section{INTRODUC̣ÃO}

Marco Polo descreve uma ponte, pedra por pedra. Mas qual é a pedra que sustenta a ponte? Pergunta Kublai Kban. A ponte não é sustentada por esta ou aquela pedra. Responde Marco Polo, mas pela curva do arco que estas formam. Kublai Kban permanece em silêncio, refletindo. Depois acrescenta: por que falar das pedras? Só o arco me interessa. Polo responde: sem pedras o arco não existe. (CALVINO, 1990, p. 79).

O governo brasileiro ao propor a modalidade de mestrado profissional, incumbiu às universidades a missão de fazer com que o conhecimento científico atravesse os muros e ultrapasse as distâncias que a separam do setor produtivo. Este artigo tem como objetivo expor e fazer uma reflexão sobre os mestrados profissionais vistos do lugar do design.

O design traz no DNA a ciência aplicada. Segundo Forty (2007), é tarefa específica desta disciplina realizar a conjunção entre ideias e meios de produção, e para ele, o êxito comercial dos produtos é o resultado deste processo. A interrelação do design com a dinâmica da inovação é indiscutível, mas sua inserção no setor produtivo brasileiro ainda está longe de ser efetiva. $O$ afastamento entre universidade e empresa dificulta a interação. Estamos há décadas alargando estas distâncias, alimentando a cultura da separação de forma silenciosa. Se faz necessário construir pontos de tangência para que os fluxos de conhecimentos possam eliminar este apartamento construído ao longo dos anos.

Enquanto países como os Estados Unidos, Coreia do Sul e a Finlândia, dentre outros, já desfrutam deste relacionamento há décadas, nós estamos iniciando este processo. Seria injusto não reconhecer as diversas iniciativas e cooperações entre universidade e empresa, realizadas anteriormente com sucesso e mérito, mas seria também um erro não reconhecer que muitas encontram-se restritas a algumas áreas do conhecimento.

A ressignificação do ensino universitário por meio da criação dos mestrados profissionais, institutos de ciência e tecnologia, leis como a da Inovação (2004) e a do Bem (2005), programas como o RHAE, tem sido demonstrações claras de políticas públicas necessárias para pavimentar as vias que atravessem os espaços, cheios de preconceitos, que separam o setor produtivo e a academia. Se faz necessário criar caminhos que possam suportar a colaboração mútua destes dois setores. Unir pontos tão distantes requer criar alicerces sólidos e muitas vezes, isso significa ter que escavar o próprio terreno das instituições, afrontar paradigmas, abrir-se à novos desafios. Mas isso não é uma tarefa fácil, 
pois, apesar de todos os benefícios que a mudança promete, concordamos com Forty (2007) quando afirma que queremos as melhorias propostas pela mudança, mas quando esta nos impõe perdas, nossa tendência é resistir.

A resistência inicial entre universidade e empresa, mostra-se pois como processo natural, mas os influxos do conhecimento provocados pelos pontos de tangência haverão de oxigenar esta relação, permitindo a produção de novos conhecimentos que romperão o isolamento destes setores, historicamente construído. Para Schopenhauer (2011), a academia prefere a prática da produção do conhecimento indireto em detrimento daquele direto, com grande prejuízo para a ciência e isso impede o aluno de tecer, por ele mesmo, a relação das coisas.

A produção atual do conhecimento cientifico brasileiro é reconhecidamente significativa, quando comparada com outros países. Contribuímos mais com a produção científica global do que com o PIB. Porém, é celebre o distanciamento socioeconômico desta produção. A baixa aplicabilidade é uma forte marca da separação destes setores. A indústria brasileira surge e mantem-se ainda distante da produção acadêmica.

Em 2012 a produção científica, apenas do banco de dados da Scopus, foi de $2,45 \%$ em relação a produção mundial e a contribuição no PIB foi de $2,7 \%{ }^{22}$ O investimento governamental em C\&T em 2008 foi de 1,45\% do PIB, enquanto as empresas investiram no mesmo período, 0,28\% do PIB. Esta diferença enfatiza o baixo investimento das indústrias brasileiras na dinâmica da inovação, além do mais, os dados reportados pela pesquisa do PINTEC / IBGE mostram que, no biênio 2009-2011, em valores absolutos, em um total de 128.699 empresas, 45.950 apresentaram-se como inovadora, mas que deste total, 38.335 foi inovação em processos e só 23.282 inovação em produtos. Entre as empresas que não promoveram nenhum tipo de inovação, 78,4\% afirmaram que isso decorreu do alto custo necessário, $65,6 \%$ o risco e $61,2 \%$ a falta de qualificação.

\section{A origem da separação}

Os primeiros empreendedores brasileiros, do recente processo de industrialização, iniciado praticamente nos anos 50, não passaram pelos bancos das universidades e não necessitaram destas para construir ou gerir suas empresas. O olhar de desconfiança era natural, pois não sabiam ao certo o que se produzia por traz daqueles muros que abrigava a elite intelectual brasileira.

22 Coordenação-Geral de Indicadores (CGIN) - ASCAV / SEXEC - Ministério da Ciência, Tecnologia e Inovação (MCTI) 
Mas a segunda geração, os filhos destes pioneiros, tiveram a experiência acadêmica. É inevitável o questionamento sobre motivo pelo qual se mantêm este distanciamento. A relatividade do tempo seria uma possibilidade de resposta, pois na academia se pensa a longo prazo, enquanto nos chamados setores produtivos, as respostas às exigências do mercado são urgentes. Mas existem outras hipóteses que podem ser mais assertivas: o ensino é efetuado de forma distante da realidade do entorno da própria universidade, causando inevitáveis distorções quando se procura aplicá-lo. Outra hipótese possível é a existência de uma certa preocupação com esta aproximação, que entre outros inconvenientes, poderia contaminar o desenvolvimento do ensino e da pesquisa acadêmica.

Os empresários se mantêm reticentes com relação aos pesquisadores, pela imagem estereotipada de um profissional sonhador, fora do mundo, atuando em um tempo próprio e que afronta outros problemas distante do dia-a-dia empresarial. As universidades, por sua vez, veem com desconfiança a aproximação dos representantes do capital. Surge como primeira hipótese a necessidade de resolução de problemas a baixo custo que proporcione maior lucratividade, em dissonância com o tempo acadêmico. Estes são alguns dos impasses que enfrentamos nesta relação e para superá-los se faz necessário a simbólica construção das pontes para ligar as bases do nosso desenvolvimento.

\section{A construção de pontes}

Construir pontes que liguem estes dois mundos separados historicamente envolvem desafios de todas as áreas. Para uma união efetiva e eficaz, acreditamos ser fundamental não nos vermos como partes isoladas, pois universidade e setor produtivo são partes integrantes do setor econômico e por sua vez responsável pelo bem estar social.

O governo brasileiro, por meio do Plano Nacional de Pós Graduação - PNPG- 2011-2020 (BRASIL, 2010), reconhece que a inovação é um dos fatores decisivos para o desenvolvimento socioeconômico de uma nação. Nos últimos anos, a expectativa que a universidade desempenhe importante papel na promoção da inovação junto ao setor produtivo brasileiro, cresceu significativamente.

Fomentar a pesquisa científica junto às empresas e incentivar sua participação nas pesquisas da universidade, se tornou meta imprescindível, pois sem recursos e sem a produção de conhecimento, não promoveremos a inovação. Hoje, mais da metade do PIB dos países desenvolvidos é resultado da dinâmica da inovação. Existe um consenso de que o conhecimento cientifico- 
tecnológico e a inovação são patrimônios sociais que contribuem para o bem estar coletivo.

A intercessão entre ciência, tecnologia e a empresa é vista, portanto, como um modelo impulsionador do desenvolvimento do setor produtivo e motor da ampliação da produtividade e da competitividade. A universidade, reconhecida pela pela excelência de seus pesquisadores e também pela capacidade de produção e difusão do conhecimento científico, coloca-se em posição estratégica na dinâmica da inovação. A multidisciplinaridade, a interdisciplinaridade e a transdisciplinaridade são características da academia, ou como prefere Morin (2001), a ciência é um campo inter-poli-transdisciplinar, pois os problemas invadem as disciplinas, rompem as fronteiras, fazem circular os conceitos, provocam o nascimento de disciplinas híbridas, formam se os complexos. E todas são características fundamentais ao processo de inovação.

Sem dúvidas dispomos de todas as pedras necessárias para a construção de dos arcos que permitirão a construção de pontes sólidas e profícuas. Resta o trabalho de assentá-las, colocando-as nas posições e sequências corretas.

\section{O novo papel da Universidade}

A mudança de entendimento sobre o papel da universidade coincide com a revolução digital e o processo de globalização. A centralidade da tecnologia e da ciência na liderança do processo econômico, tem proporcionado o surgimento de novos serviços, produtos intangíveis e o consumo de experiências. Para o IBGE/PINTEC, em 2011, o setor de serviços foi aquele que mais investiu em inovação. Porém a inovação brasileira conta ainda muito pouco com a pósgraduação, apresentando um baixo nível de inserção de pós- graduados. Mais de $80 \%$ da inovação nas empresas são realizadas por graduados e pessoas do nível médio ou fundamental. Segundo o Centro de Gestão e Estudos Estratégicos (CGEE), em 2010 o Brasil apresentava 1,4\% dos seus doutores na indústria de transformação, índice ainda baixo para o padrão de competitividade e desenvolvimento atual.

Em 2004 a Comunidade Europeia lança o protocolo “Europa do conhecimento 2020", visando concentrar os esforços em três grandes áreas: educação; pesquisa e inovação; sociedade digital. O documento revisa a função da universidade, criando "a terceira missão", que vai além das tradicionais funções, ensino e pesquisa. (GIBBONS et al., 1994).

A chamada "terceira missão" tem como objetivo, dentre outros, habilitar os pesquisadores oriundos da academia a transferir e difundir conhecimentos 
científicos e tecnológicos à sociedade. Espera-se, portanto, a formação de pesquisadores capazes de responder as demandas sociais de seu tempo. Da mesma forma, acredita-se que essa ação abrirá novos canais para aportes financeiros à universidade e principalmente à pesquisa. Observou-se que existe uma relação estreita entre volume de investimentos em pesquisa e a inovação, desta forma a terceira missão aumentaria o volume financeiro investido, mas ao mesmo tempo, coloca a universidade em uma função empreendedora.

O sistema de "universidade empreendedora" (CLARK, 1998) praticado inicialmente na Inglaterra, torna-se sedutor para todo o mundo. As universidades americanas tornaram-se excelência, principalmente o Massachusetts Institute of Technology (MIT) e a Stanford University. Esse modelo permite a transferência de conhecimento à empresa e até mesmo desempenhar o papel de agente comercial de suas próprias pesquisas, desenvolvimento e inovações (PDI). A universidade empreendedora parte, portanto, do conceito de tripla hélice, qual seja, governo, universidade e empresa. Este tipo de arranjo incentiva, de forma contundente, a dinâmica da inovação.

O governo brasileiro editou em 2008 a Lei do Bem que facilita e incentiva a transferência de tecnologia e conhecimento das universidades públicas aos setores privados. Cria as bases para um ambiente híbrido entre setores acadêmicos e empresariais, permitindo, como na Comunidade Europeia, à própria universidade explorar economicamente o conhecimento produzido. Por meio desta lei, o pesquisador passa a ser o agente da inovação, podendo ser remunerado também pelo setor produtivo. As universidades lançam assim as bases para o empreendedorismo. A Lei do Bem impulsiona mudanças significativas na concepção de universidade no Brasil, país que até o início da primeira década do século XXI, estava investindo, ainda fortemente, nos padrões de qualidade dos produtos e serviços.

A sinergia pretendida pela tríplice hélice, traz ganhos significativos para os seus atores: a universidade consegue acessar recursos adicionais para o financiamento de pesquisas, ganha mais autonomia fundada no aumento de recursos, passa a ter maior acesso ao conhecimento produzido pelas empresas, maior inserção regional, aumenta a possibilidade de internacionalização e cria maior inclusão para pesquisadores e alunos. A empresa ganha competitividade com a inserção da inovação na atividade de $P \& D$, além de aumentar a capacidade de atração de talentos e incentiva a educação continuada. A sociedade é beneficiada com fortalecimento da capacidade inovadora, aumento do PIB, melhoria na qualidade dos produtos e serviço, elevação do nível de arrecadação e promoção do bem estar social. 
Muitos autores veem neste processo um risco constante às atividades tradicionais de ensino e pesquisa. Acreditam que o desenvolvimento desta nova universidade pode trazer ao ensino uma visão de curto prazo, com a intenção de atender às exigências de mercado, e à pesquisa uma pauta investigativa restrita às imposições econômicas. Salientam, da mesma forma, o alto custo destas pesquisas e de sua transferência. Esta nova função universitária poderia, portanto, comprometer o desenvolvimento de atividades tradicionais da universidade.

Apesar de acreditamos no efeito positivo da relação universidadeempresa, vemos como lícitas estas preocupações. Estas relações devem necessariamente ser monitoradas no intuito de evitar impactos indesejados e prejudiciais as outras tantas funções universitárias. O desenvolvimento de mecanismos que permitam este controle é fundamental, pois é natural que o resultado deste processo provoque mudanças em ambas as partes.

Atualmente é possível desenvolver estudos aprofundados sobre os efeitos deste relacionamento junto às universidades públicas e privadas, mesmo que de forma preliminar, pois muitos mestrados e doutorados acadêmicos desenvolvem atividades de pesquisa aplicada, mesmo antes da Lei do Bem. O inverso também mostra-se verdadeiro. Nos recentes mestrados profissionais tem-se desenvolvido pesquisas autocentradas, pois muitas vezes, os pesquisadores envolvidos são extremamente qualificados e preparados para as atividades acadêmicas, com larga experiência em pesquisa de base, distantes do processo produtivo e da pesquisa aplicada. Estamos no epicentro de um processo de mudança e por isso atravessando fases de transição que precisam ser acompanhadas.

As universidades brasileiras são estruturadas sob três pilares: o ensino, a pesquisa e a extensão. A criação dos mestrados profissionais e a mudança estrutural que assistimos, assim como em outros países, nos põe algumas perguntas: não estaríamos, à exemplo da Comunidade Europeia, criando um novo pilar por meio da pós-graduação? Observamos um modelo próprio, híbrido e estruturando em dois eixos, o acadêmico e o profissional. Os mestrados profissionais, não seriam contudo, a quarta missão? E porque estaríamos criando dois eixos? Encontramos algumas destas respostas nos documentos setoriais do PNPG 2011- 2020 (BRASIL, 2010, p. 265) que afirma que "O mestrado profissional é a forma mais visível de disputas ideológicas entre lideranças acadêmicas que defendem tradições versus inovações como se fossem excludentes, reforçando a inércia estrutural e a hipervalorização do eixo acadêmico [...]."

São muitos os desafios que envolvem a inovação e a participação 
universitária neste processo. Estes desafios nos impõem perguntas importantes e que guiarão o nosso trabalho daqui para frente, quais sejam: como construir um projeto curricular que atenda a estas necessidades? E ainda, como conduzir este projeto de forma sustentável e rentável? Como atrair as empresas a desenvolver projetos junto à universidade? Como formar parcerias? São perguntas constantes nos mestrados profissionais.

A introdução da universidade na dinâmica da inovação gera novas funções como consultorias, prestação de serviços, formação de profissionais específicos, assessoria tecnológica, bem como, geração de novos conhecimentos por meio da pesquisas de materiais, processos, produtos, etc. Espera-se, portanto, que esta nova missão altere o processo do desenvolvimento de produtos (P\&D), que retroalimentará o processo, criando a tríade da pesquisa, desenvolvimento e inovação (PDI).

Construir um currículo que possa atender a todas estas demandas, requer uma visão clara dos objetivos macro do mestrado profissional e onde se pretende atuar, mas em primeiro lugar temos que ter a consciência de que atravessamos um momento de transição, onde se mostra fundamental pavimentar o terreno e construir bases sólidas para a feitura das pontes. É preciso valorizar as políticas que solidifiquem esta passagem, para que se construa entre empresa e universidade uma via de mão dupla de ensino, aprendizagem e pesquisa.

No mestrado profissional atendemos à qualificação de estudantes que na sua maioria, já estão no mercado de trabalho, portanto os conhecimentos trazidos ao meio acadêmico é essencial, pois na dinâmica da inovação é fundamental a construção conjunta dos saberes múltiplos. Esta condição nos impõem um currículo flexível, onde estes conhecimentos sejam valorizados e potencializados. Sobre esta base elencamos algumas outras, sem a pretensão de esgotarmos as necessidades, já que o mestrado profissional traz consigo a flexibilidade.

(a)Elaborar estratégias que atuem sob o contexto socioeconômico regional, visando o processo da dinâmica da inovação aplicada localmente e só então impulsiona-la à atuação nacional e internacional.

(b)Estruturar o mestrado no intuito de facilitar a qualificação de recursos humanos na empresa.

(c) Promover e estimular ações de capacitação empreendedora, pois, tanto a universidade como o próprio pesquisador podem ser agentes da exploração econômica do conhecimento desenvolvido. 
(d)Fomentar estratégias integradoras estimulando 0 trabalho interdisciplinar, internamente e externamente à universidade, valorizando o cruzamento e a construção coletiva dos saberes, que são a base da inovação.

(e)Dedicar especial atenção a qualificação para a docência. Na área do design, existe crescente necessidade de quadros docentes qualificados, portanto, o currículo deve prever também esta ação.

(f) Fomentar o desenvolvimento de tecnologias sociais vinculadas à sustentabilidade em seus três pilares: social; econômico e ambiental.

(g)Incentivar o processo reflexivo, fazer com que o profissional reflita sobre sua atuação profissional e sobre os processos por ele executados.

(h)Definir como meta a pesquisa aplicada construída coletivamente com a empresa.

(i) Desenvolver o currículo com a perspectiva do ensino continuado, pois estamos vivendo em uma sociedade aprendente e em constante transformação tecnológica, onde a empregabilidade e a inclusão social dependem deste tipo de aprendizagem.

(j) Incentivar os pesquisadores ao trabalho em grupo e a produção coletiva.

(k)Implantar internamente a dinâmica da inovação para atender as demandas do mundo do trabalho e da academia "[...] apoiando a construção e a testagem de modelos de ensino híbridos, articuladores dos espaços acadêmicos e profissionais dos diferentes níveis e instituições de ensino." Fischer e Waiandt (2012, p. 102).

(I) Desenvolvermos estratégias de atuação no ensino médio e fundamental.

(m)Incentivar a criatividade e desenvolver a habilidade de aprender.

Naturalmente seria difícil fazer um espelho de todo o teor necessário ao mestrado profissional, e acreditamos que este não é o proposito central deste artigo, que certamente deixou a parte outros conteúdos importantes. Mas dentro deste arcabouço de referências, necessidades e desafios não poderíamos deixar de lado a sustentabilidade que vai além de sua criação. Até o presente momento não existem bolsas de estudos oferecidas diretamente ao mestrado profissional. A intenção governamental é que as universidades busquem recursos no setor produtivo e/ou por meio de editais de incentivo às pesquisas aplicadas em parceria com as empresas. Neste período de transição 
é necessário investir nesta parceria, e investir significa esperar um tempo significativo para obter retorno, pois teremos que mudar a cultura empresarial e isso seguramente demanda tempo.

As universidade privadas começaram a fazer os cálculos deste retorno, e as públicas apresentam dificuldades na captação de alunos, já que as mensalidades só podem ser pagas pelas empresas, que por sua vez se queixam da dupla tributação. Sabemos da importância da dinâmica da inovação e da importância decisiva das universidades neste processo, mas para coloca-la em funcionamento, de forma retro-alimentável e rentável, significa vencer uma cultura secular de separação.

Como vimos anteriormente, este processo colaborativo entre empresa e universidade pode gerar prestação de serviços de diversas naturezas, contudo, este tipo de produção de recursos são insuficientes para que haja aportes financeiros significativos à pesquisa, que normalmente apresentam custos elevados. Estes investimentos, necessariamente, deverão ser oriundos das empresas e fruto das "pontes" a serem construídas constantemente pelo mestrado. Como atrair as empresas no curto prazo, é outro desafio e com menos respostas prontas que os desafios anteriores, pois é necessário adotar sempre novas estratégias e estar constantemente inovando. É um trabalho lento e laborioso desenvolvido pelos atores envolvidos.

O governo dispõe os editais de incentivo a inovação, mas praticamente só as grandes empresas e as universidades respondem, pois nas pequenas e médias empresas não existem pessoas disponíveis ou capacitadas a escrever o projeto. Vemos como de suma importância promover o diálogo entre os atores: universidade, governo e empresa, para que sejam criadas estratégias e políticas públicas conjuntas que possam se somar as já existentes. Melhorar a divulgação das políticas de incentivo à inovação tecnológica com intuito de estimular a participação da iniciativa privada.

Construir pontes unindo territórios tão distantes não é uma tarefa fácil, mas nem tão pouco impossível. O tempo necessário para esta construção depende do empenho coletivo. Atingir uma densidade de inovação para sermos competitivos só será possível com políticas de fomento multi-setoriais, envolvendo todos os atores.

A universidade brasileira responde hoje a uma crescente expectativa do papel social a ser desempenhado, dentre eles, tratamos aqui da dinâmica de inovação, onde expulsemos alguns desafios de curto prazo, que correspondem ao processo de adaptação que atravessamos. As mudanças são significativas, e não se trata de levar a inovação ao setor produtivo. A inovação é uma dinâmica 
que afeta tanto os atores que a produzem como a sociedade a qual estão inseridos. Mudanças exigem quebra de paradigmas e reflexões na busca de novos caminhos.

\section{REFERÊNCIAS}

BRASIL. Ministério de Educação. Coordenação de Aperfeiçoamento de Pessoal de Nível Superior. Plano Nacional de Pós-Graduação - PNPG 2011-2020. Brasília: CAPES, 2010. 2 Volumes.

BRASIL. Secretaria Executiva do Ministério da Ciência, Tecnologia e Inovação - MCTI. Incentivos fiscais. Disponível em:<www.mcti.gov.br/ incentivos fiscais>. Acesso em: 3 abr. 2014.

BRASIL. Secretaria Executiva do Ministério da Ciência, Tecnologia e Inovação - MCTI. Estratégia nacional de ciência, tecnologia e inovação 2012-2015: balanço das atividades estruturantes 2011. Brasília: MCTI, 2012.

CALVINO, Italo. As cidades invisíveis. São Paulo: Companhia das Letras, 1990.

CENTRO DE GESTÃO E ESTUDOS ESTRATÉGICOS - CGEE. Doutores 2010: estudos da demografia da base técnica- cientifica Brasileira. Brasília: CGEE, 2010.

CLARK, Burton. Creating entrepreneurial universities: organisational pathways of transformation. New York:Elsevier Science, 1998.

FISCHER, Tânia; WAIANDT, Claudiani. A educação profissional e os desafios do desenvolvimento brasileiro. Revista Brasileira de PósGraduação, Brasília, v. 9, n. 16, 2012.

FORTY, Adrian. Objetos de desejo - design e sociedade desde 1750. São Paulo: Cosac Naify, 2007.

GIBBONS, Michael; LIMOGE, Camille; NOWOTNY, Helga; SCHWARTZMAN, Simon; SCOTT, Peter; TROW, Martin. The new production of knowledge: dynamics of science and research in contemporary societies. New Delhi: Sage puublications, 1994.

HENRÍQUEZ, Liney Manjarrés; GARCÍA, Antonio Gutiérrez. Relaciones Universidad-Empresa y produccioón científica de los académicos. 
Fundacion española para Ciencia y Tecnologia. Valencia: Ingenio working paper series. 2009.

IBGE. Pesquisa de inovação tecnológica - PINTEC 2011. Disponível em: <http://www.ibge.gov.br/home/presidencia/noticias/imprensa/ppts/0 0000015562512192013253204166348.pdf>. Acesso em: 5 abr. 2014.

MORIN, Edgar. A cabeça bem-feita: repensar a reforma e reformar o pensamento. Rio de Janeiro: Bertrand Brasil, 2001.

SCHOPENHAUER, Arthur. O mundo como vontade e representação. 4. ed. Rio de Janeiro: Contraponto Ltda., 2011.

Recebido em:14/07/14

Aprovado em:25/07/14 